\title{
Application of Simultaneous Equation in Finance Research
}

\author{
By Carl R. Chen and Cheng Few Lee
}

\section{A. Introduction}

Empirical finance research often employs a single equation for estimation and testing. However, single equation rarely happens in the economic or financial theory. Using OLS method to estimate equation(s) which should otherwise be treated as a simultaneous equation system is likely to produce biased and inconsistent parameter estimators. To illustrate, let's start with a simple Keynesian consumption function specified as the follow:

$$
\begin{aligned}
& C_{t}=\alpha+\beta Y_{t}+\mu_{t} \\
& Y_{t}=C_{t}+I_{t} \\
& I_{t}=I_{0}
\end{aligned}
$$

Where $C_{t}$ is the consumption expenditure at time t, $Y_{t}$ is the national income at time t, $I_{t}$ is the investment expenditure at time $\mathrm{t}$, which is assumed fixed at $I_{0}$, and $\mu_{t}$ is the stochastic disturbance term at time t. Equation (1.1) is the consumption function; Equation (1.2) is the equilibrium condition (national income accounting identity); and equation (1.3) is the investment function. Some of the variables in the model are endogenous, others are exogenous. For example, $C_{t}$ and $Y_{t}$ are endogenous, meaning they are determined within the model. On the other hand, $I_{t}$ is the exogenous variable, which is not determined in the model, hence not correlated with $\mu_{t}$.

A simultaneous equation bias arises when OLS is applied to estimate the consumption function because $Y_{t}$ is correlated with the disturbance term $\mu_{t}$, which violates the OLS assumption that independent variables are orthogonal to the disturbance term. To see this, through a series of substitutions, we can obtain the reduced form equations from the structural equations (1.1) through (1.3) as:

$$
\begin{aligned}
& C_{t}=\frac{\alpha}{1-\beta}+\frac{\beta}{1-\beta} I_{0}+\frac{\mu_{t}}{1-\beta} \\
& Y_{t}=\frac{\alpha}{1-\beta}+\frac{1}{1-\beta} I_{0}+\frac{\mu_{t}}{1-\beta}
\end{aligned}
$$


Based upon Equation (2.2), clearly $Y_{t}$ is correlated with the disturbance term, $\mu_{t}$, which violates the OLS assumption that independent variables and the disturbance term are uncorrelated. This bias is commonly referred to in the literature as the simultaneous equation bias. Furthermore, the OLS estimate of $\beta$ in equation (1.1) is not only bias, but also inconsistent, meaning $\beta$ estimate does not converge to the true $\beta$ when the sample size increases to vary large.

\section{B. Two-stage and three-stage least squares method}

To resolve the simultaneous equation bias problem as illustrated in Section A, in this section we discuss two popular simultaneous equation estimation methods. Different methods are available to handle the estimation of a simultaneous equation model: Indirect least squares, instrumental variable procedure, two-stage least squares, three-stage least squares, limited information likelihood method, and full information maximum likelihood method, just to name a few. In this section, we will focus on two methods that popular statistical and/or econometric software are readily available.

\section{Identification problem}

Before getting into the estimation methods, it is necessary to discuss the "identification problem". Identification problem arises when we can not identify the difference between, say, two functions. Consider the demand and supply model of gold. The structure equations can be written as:

$$
\begin{aligned}
& Q_{d}=\alpha_{0}+\alpha_{1} P+\varepsilon \\
& Q_{s}=\beta_{0}+\beta_{1} P+e \\
& Q_{d}=Q_{s}=Q
\end{aligned}
$$

Equation (3.1) is the demand for gold function, where the demand $Q_{d}$ is determined by the price of gold, $P$; Equation (3.2) is the supply of gold, and it is a function of gold price; Equation (3.1) is an identity stating the market equilibrium. Can we apply the OLS method to Equations (3.1) and (3.2) to obtain parameter estimates? To answer this question, we first obtain the "reduced form" equations for $P$ and $Q$ through substitutions.

$$
P=\frac{\beta_{0}-\alpha_{0}}{\alpha_{1}-\beta_{1}}+\frac{\varepsilon-e}{\alpha_{1}-\beta_{1}}
$$




$$
Q=\frac{\alpha_{1} \beta_{0}-\alpha_{0} \beta_{1}}{\alpha_{1}-\beta_{1}}+\frac{\alpha_{1} \varepsilon-\beta_{1} e}{\alpha_{1}-\beta_{1}}
$$

Obviously it is impossible to estimate Equations (4.1) and (4.2) using OLS method because there are four parameters $\left(\alpha_{0}, \alpha_{1}, \beta_{0}\right.$, and $\left.\beta_{1}\right)$ to be estimated, but there are only two equations. Therefore, we cannot estimate the parameters in the structure equations. This is the situation called "under-identification".

To differentiate demand equation from supply equation, now suppose we assume that demand curve for gold may shift due to the changes in economic uncertainty, which can be proxied by, say, stock market volatility, $V$, which is assumed to be exogenous. Hence Equations (3.1) and (3.2) can be modified as:

$$
\begin{aligned}
& Q_{d}=\alpha_{0}+\alpha_{1} P+\alpha_{2} V+\varepsilon \\
& Q_{s}=\beta_{0}+\beta_{1} P+e
\end{aligned}
$$

The reduced form becomes

$$
\begin{aligned}
P & =\frac{\beta_{0}-\alpha_{0}}{\alpha_{1}-\beta_{1}}-\frac{\alpha_{2}}{\alpha_{1}-\beta_{1}} V+\frac{\varepsilon-e}{\alpha_{1}-\beta_{1}} \\
& =\gamma_{0}+\gamma_{1} V+\pi_{1} \\
Q & =\left(\beta_{0}+\beta_{1} \gamma_{0}\right)+\beta_{1} \gamma_{1} V+\frac{\alpha_{1} \varepsilon-\beta_{1} e}{\alpha_{1}-\beta_{1}} \\
& =\lambda_{0}+\lambda_{1} V+\pi_{2}
\end{aligned}
$$

Because $V$ is assumed exogenous and uncorrelated with residuals $\pi_{1}$ and $\pi_{2}$, OLS can be applied to the reduced form equations (6.1) and (6.2), and obtain estimators of $\gamma_{0}, \gamma_{1}, \lambda_{0}$, and $\lambda_{1}$. Examine Equation (6.2), we find that $\lambda_{0}=\beta_{0}+\beta_{1} \gamma_{0}$, and $\lambda_{1}=\beta_{1} \gamma_{1}$. Since $\gamma_{0}, \gamma_{1}, \lambda_{0}$, and $\lambda_{1}$ are all obtained from the OLS estimates, $\beta_{0}$ and $\beta_{1}$ can be solved. Therefore, the supply function (Equation (6.2)) is said to be identified. However, from the demand function, we find that

$$
\gamma_{0}=\frac{\beta_{0}-\alpha_{0}}{\alpha_{1}-\beta_{1}}, \quad \text { and } \quad \gamma_{1}=\frac{\alpha_{2}}{\alpha_{1}-\beta_{1}}
$$


Since there are only two equations, we can not possibly estimate three unknowns, $\alpha_{0}, \alpha_{1}$, and $\alpha_{2}$, hence the demand function is not identified. Based upon the discussions of Equations (3.1) and (3.2), we thus know that in a two-equation model, if one variable is omitted from one equation, then this equation is identified. On the other hand, there is no omitted variable in Equation (3.1), hence the demand function is not identified.

Now let's further modify Equations (3.1) and (3.2) as follow:

$$
\begin{aligned}
& Q_{d}=\alpha_{0}+\alpha_{1} P+\alpha_{2} V+\varepsilon \\
& Q_{s}=\beta_{0}+\beta_{1} P+\beta_{2} D+e
\end{aligned}
$$

All variables are defined as before except now we have added a new variable $D$ in the supply equation. Let $D$ be the government deficit of Russia, which is assumed exogenous to the system. When Russia's budget deficit deteriorates, the government increases the gold production for cash. The reduced form of $P$ and $Q$ based upon Equations (5.1) and (5.2) is

$$
\begin{aligned}
P & =\frac{\beta_{0}-\alpha_{0}}{\alpha_{1}-\beta_{1}}-\frac{\alpha_{2}}{\alpha_{1}-\beta_{1}} V+\frac{\beta_{2}}{\alpha_{1}-\beta_{1}} D+\frac{\varepsilon-e}{\alpha_{1}-\beta_{1}} \\
& =\gamma_{0}+\gamma_{1} V+\gamma_{2} D+\pi_{1} \\
Q & =\left(\alpha_{0}+\alpha_{1} \gamma_{0}\right)+\left(\alpha_{1} \gamma_{1}+\gamma_{2}\right) V+\alpha_{1} \gamma_{2} D+\frac{\alpha_{1} \varepsilon-\beta_{1} e}{\alpha_{1}-\beta_{1}} \\
& =\lambda_{0}+\lambda_{1} V+\lambda_{2} D+\pi_{2}
\end{aligned}
$$

Based upon the OLS estimates of Equations (8.1) and (8.2), we can obtain unique estimates for the structure parameters $\alpha_{0}, \alpha_{1}, \alpha_{2}, \beta_{0}, \beta_{1}$, and $\beta_{2}$, hence both the demand and supply functions are identified. In this case, we call the situation as "exactly identified".

In a scenario when there are multiple solutions to the structure parameters, the equation is said to be "over-identified". For example, in Equations (9.1) and (9.2), we modify the supply equation by adding another exogenous variable, q, representing lagged quantity of gold produced (i.e., supply of gold in the last period), which is predetermined. 


$$
\begin{aligned}
& Q_{d}=\alpha_{0}+\alpha_{1} P+\alpha_{2} V+\varepsilon \\
& Q_{s}=\beta_{0}+\beta_{1} P+\beta_{2} D+\beta_{3} q+e
\end{aligned}
$$

The reduced form becomes

$$
\begin{aligned}
P & =\frac{\beta_{0}-\alpha_{0}}{\alpha_{1}-\beta_{1}}-\frac{\alpha_{2}}{\alpha_{1}-\beta_{1}} V+\frac{\beta_{2}}{\alpha_{1}-\beta_{1}} D+\frac{\beta_{3} q}{\alpha_{1}-\beta_{1}}+\frac{\varepsilon-e}{\alpha_{1}-\beta_{1}} \\
& =\gamma_{0}+\gamma_{1} V+\gamma_{2} D+\gamma_{3} q+\pi_{1} \\
Q & =\left(\alpha_{0}+\alpha_{1} \gamma_{0}\right)+\left(\alpha_{1} \gamma_{1}+\gamma_{2}\right) V+\alpha_{1} \gamma_{2} D+\alpha_{1} \gamma_{3}+\frac{\alpha_{1} \varepsilon-\beta_{1} e}{\alpha_{1}-\beta_{1}} \\
& =\lambda_{0}+\lambda_{1} V+\lambda_{2} D+\lambda_{3} q+\pi_{2}
\end{aligned}
$$

Based upon Equations (10.1) and (10.2), we find $\alpha_{1} \gamma_{2}=\lambda_{2}$, hence structure equation parameter $\alpha_{1}$ can be estimated as $\gamma_{2} / \lambda_{2}$. However, we also find $\alpha_{1} \gamma_{3}=\lambda_{3}$, hence $\alpha_{1}$ can also take another value, $\gamma_{3} / \lambda_{3}$. Therefore, $\alpha_{1}$ does not have a unique solution, and we say the model is "over-identified".

The condition we employ in the above discussions for model identification is the so-called "order condition of identification". To summarize the order condition of model identification, a general rule is that the number of variables excluded from an equation must be $\geq$ the number of structural equations. ${ }^{1}$

Although "order condition" is a popular way of model identification, it provides only a necessary condition for model identification, not a sufficient condition. Alternatively, "rank condition" provides both necessary and sufficient conditions for model identification. An equation satisfies the rank condition if and only if at least one determinant of rank (M-1) can be constructed from the column coefficients corresponding to the variables that have been excluded from the equation, where $\mathrm{M}$ is the number of equations in the system. However, "rank condition" is more complicate than "order condition", and it is difficult to determine in a large simultaneous equation model. The following example based upon Equations (11.1) through (11.3) provides some basic ideas about "rank condition". Note Equations (11.1) through (11.3) are similar to Equations (5.1), (5.2), and (3.3) with terms rearranged.

\footnotetext{
1 The discussions of the order condition draw heavily from Ramanathan (1995).
} 
$Q_{d}-\alpha_{0}-\alpha_{1} P-\alpha_{2} V=\varepsilon$

$Q_{s}-\beta_{0}-\beta_{1} P=e$

$Q_{d}-Q_{s}=0$

In the following table, all structural parameters are stripped from the equations and placed in a matrix.

\begin{tabular}{|l|l|l|l|l|l|}
\hline & \multicolumn{5}{|l|}{ Variables } \\
\hline Equations & Intercept & $Q_{d}$ & $Q_{s}$ & $P$ & $V$ \\
\hline Equ. (11.1) & $-\alpha_{0}$ & 1 & 0 & $-\alpha_{1}$ & $-\alpha_{2}$ \\
\hline Equ. (11.2) & $-\beta_{0}$ & 0 & 1 & $\beta_{1}$ & 0 \\
\hline Equ. (11.3) & 0 & 1 & -1 & 0 & 0 \\
\hline
\end{tabular}

Since variables $Q_{d}$ and $V$ are excluded from Equation (11.2), the determinant of remaining parameters in columns $Q_{d}$ and $V$ is

$\left|\begin{array}{cc}1 & -\alpha_{2} \\ 1 & 0\end{array}\right|=\alpha_{2}$

Because this has a rank of 2 , which is equal to the number of equations subtracts 1 , Equation 2 is identified. On the other hand, a determinant of rank 2 cannot be constructed for Equation (11.1) because it has only one zero coefficient, hence Equation (11.1) is "under-identified". 2

\section{Two-stage least squares}

Two-stage least squares (2SLS) method is easy to apply and can be applied to a model that is exactly- or over-identified. To illustrate, let's use Equations (7.1) and (7.2) for demonstration, and rewrite them as the follows:

\footnotetext{
${ }^{2}$ For more detailed discussions of the rank condition, see econometric books such as Greene (2003), Judge et al. (1985), Fisher (1966), Blalock (1969), and Fogler and Ganapathy (1982).
} 
$Q_{d}=\alpha_{0}+\alpha_{1} P+\alpha_{2} V+\varepsilon$

$Q_{s}=\beta_{0}+\beta_{1} P+\beta_{2} D+e$

Based upon the "order condition", Equations (12.1) and (12.2) each has one variable excluded from the other equation, which is equal to the number of equations minus one. Hence the model is identified.

Since endogenous variable $P$ is correlated with the disturbance term, the first stage for the 2SLS calls for the estimation of "predicted $P$ " $(\hat{P})$ using a reduced form containing all exogenous variables. To do this, we can apply the OLS to the following equation:

$P=\eta_{0}+\eta_{1} V+\eta_{2} D+\tau$

OLS will yield unbiased and consistent estimation because both $V$ and $D$ are exogenous, hence not correlated with the disturbance term $\tau$. With the parameters in equation (13) estimated, the "predicted $P$ " can be calculated as:

$\hat{P}=\hat{\eta}_{0}+\hat{\eta}_{1} V+\hat{\eta}_{2} D$.

This $\hat{P}$ is the instrumental variable to be used in the second stage estimation, and is not corrected with the structure equation disturbance term. Substituting $\hat{P}$ into Equations (12.1) and (12.2), we have

$Q_{d}=\alpha_{0}+\alpha_{1} \hat{P}+\alpha_{2} V+\varepsilon$

$Q_{s}=\beta_{0}+\beta_{1} \hat{P}+\beta_{2} D+e$

Since $\hat{P}$ is not correlated with the disturbance terms, OLS method can be applied to Equations (14.1) and (14.2).

\section{Three-stage least squares}

The 2SLS method is a limited information method. On the other hand, the three-stage least squares (3SLS) method is a full information method. A full information method takes into account the information from the complete system, hence it is more efficient than the limited information method. Simply put, 3SLS method incorporates information obtained from the variance-covariance matrix of the system disturbance terms to estimate structural equation parameters. On the otherhand, 
2SLS method assumes that $\varepsilon$ and $e$ in Equations (14.1) and (14.2) are independent and estimates structural equation parameters separately, thus it might lose some information when in fact the disturbance terms are not independent. This section briefly explains a 3SLS estimation method.

Let the structural equation, in matrix, be:

$Y_{i}=Z_{i} \psi_{i}+\varepsilon_{i}$, where $i=1,2, \ldots \mathrm{m}$

In Equation (15), $Y_{i}$ is a vector of $n$ observations on the left-hand side endogenous variables; $Z_{i}$ is a matrix consisting of the right-hand side endogenous and exogenous variables, i.e., $Z_{i}=\left[y_{i}: x_{i}\right]$; and $\psi_{i}$ is a vector of structural equation parameters such that $\psi_{i}=\left[\alpha_{i} \vdots \beta_{i}\right]^{\prime}$. Let

$$
Y=\left(\begin{array}{l}
Y_{1} \\
\vdots \\
Y_{m}
\end{array}\right) \quad Z=\left(\begin{array}{ccc}
Z_{1} & \ldots & 0 \\
\vdots & \ddots & \vdots \\
0 & \cdots & Z_{m}
\end{array}\right) \quad \psi=\left(\begin{array}{l}
\psi_{1} \\
\vdots \\
\psi_{m}
\end{array}\right) \quad \varepsilon=\left(\begin{array}{l}
\varepsilon_{1} \\
\vdots \\
\varepsilon_{m}
\end{array}\right)
$$

Then,

$Y=Z \psi+\varepsilon$

If we multiply both sides of Equation (16) by a matrix $X^{\prime}$, where

$$
\begin{aligned}
& X^{\prime}=\left(\begin{array}{ccc}
x^{\prime} & \ldots & 0 \\
\vdots & \ddots & \vdots \\
0 & \ldots & x^{\prime}
\end{array}\right), \\
& \text { i.e., } \\
& X^{\prime} Y=X^{\prime} Z+X^{\prime} \varepsilon
\end{aligned}
$$

Then the variance-covariance matrix of the disturbance term in Equation (17), $X^{\prime} \varepsilon$ will be 


$$
E\left(X^{\prime} \varepsilon \mathcal{E}^{\prime} X\right)=\Omega \otimes x^{\prime} x=\left(\begin{array}{ccc}
\sigma_{11} x^{\prime} x & \ldots & \sigma_{1 m} x^{\prime} x \\
\vdots & \ddots & \vdots \\
\sigma_{m 1} x^{\prime} x & \cdots & \sigma_{m m} x^{\prime} x
\end{array}\right)
$$

The 3SLS structural equation parameters can thus be estimated as

$\hat{\psi}=\left\{Z^{\prime} X\left[\hat{\Omega}^{-1} \otimes\left(x^{\prime} x\right)^{-1}\right] X^{\prime} Z\right\}^{-1} Z^{\prime} x\left[\hat{\Omega}^{-1} \otimes\left(x^{\prime} x\right)^{-1}\right] X^{\prime} Y$

A question arises in the estimation process because the $\sigma^{\prime} s$ are unknown, hence the matrix $\Omega^{-1}$ is also unknown. This problem can be resolved by using the residuals from the structural equations estimated by the 2SLS to form the mean sum of residual squares and use them to estimate $\Omega^{-1}$. Standard econometric software such as SAS can be easily used to estimate Equation (19). In sum, 3SLS takes three stages to estimate the structural parameters. The first stage is to estimate the reduce form system; the second stage uses 2 SLS to estimate the $\hat{\Omega}$ matrix; and the third stage completes the estimation using Equation (19). Since $\Omega$ contains information pertinent to the correlations between disturbance terms in the structural equations, 3SLS is called a full information method. ${ }^{3}$

Since 3SLS is a full information estimation method, the parameters estimated are asymptotically more efficient than the 2SLS estimates. However, this statement is correct only if the model is correctly specified. In effect, 3SLS is quite vulnerable to model misspecifications. This is because model misspecification in a single equation could easily propagate itself into the entire system.

\section{Application of simultaneous equation in finance research}

In this section, we use an example employing the simultaneous equation model to illustrate how the system can be applied to finance research.

Corporate governance literature has long debated whether corporate executives' interest should be aligned with that of the shareholders. Agency theory argues that unless there is an incentive to align the managers' and shareholder's interests, facing the agency problem, managers are likely to exploit for personal interest at the expense of shareholders'. One way to align the interest is to make the executive compensation

\footnotetext{
${ }^{3}$ For more detailed discussions, see Ghosh (1991), Judge et al. (1985), and Greene (2003).
} 
incentive-based. Chen, Steiner, and Whyte (2006) study the effect of bank executive incentive compensation on the firm risk-taking. A single equation model of the effect of executive compensation on firm risk-taking would look like:

$$
\begin{aligned}
\text { Risk } & =\alpha_{0}+\alpha_{1}(\text { Comp })+\alpha_{2}(\text { LTA })+\alpha_{3}(\text { Capital })+\alpha_{4}(N I)+\sum_{i=5}^{m} \alpha_{i}(\text { Dgeo }) \\
& +\sum_{i=m+1}^{n} \alpha_{i}(\text { Dyear })+\mu
\end{aligned}
$$

Where Risk is measurements of firm risk; Comp is the executive incentive compensation (i.e., option-based compensation); LTA is the total assets in log form; Capital is the bank's capital ratio; NI is the non-interest income, in percentage; Dgeo is a binary variable measuring bank's geographic diversification; and Dyear is a yearly dummy variable. Chen et al. (2006) argue that OLS estimates of Equation (20) will produce simultaneity bias because executive compensation is endogenous to the model, and is likely to be correlated with the disturbance term $\mu$. Therefore, Chen et al. (2006) introduce another equation to measure executive compensation.

$$
\text { Comp }=\beta_{0}+\beta_{1}(\text { Risk })+\beta_{2}(\text { LTA })+\beta_{3}(S P)+\sum_{i=4}^{m} \beta_{i}(\text { Drate })+v
$$

Where SP is the underlying stock price and Drate is a series of dummy variables measuring annual interest rates. For example, Rate92 is defined as the T-bill rate of 1992 if the data is from year 1992; otherwise, a value of 0 is assigned to Rate92. Interest rate dummies control for the impact of interest rates on option value.

Taking Equations (20) and (21) together, we find that applying OLS to these two structural equations will not yield unbiased estimates because the right-hand-side variables include endogenous variables Comp and Risk. Therefore, Chen et al. (2006) apply 2SLS to these two equations, and Table 1 reports some of their results. Chen et al. first report OLS estimates of the risk equation and find that executive's compensation structure does not impact firm risk-taking. 2SLS results reported in Table 1, however, reveal that once the simultaneity of firm risk decision and executive compensation are taken into account, executive compensation does affect firm risk-taking. The incorrect inference derived from the OLS estimates is thus due to simultaneity bias. 
Table 1

Simultaneous Equation Model Showing the Relation between Total Risk and Option-Based Compensation Estimated Using Two-Stage Least Squares (2SLS)

\begin{tabular}{|c|c|c|c|c|}
\hline \multirow{3}{*}{$\begin{array}{l}\text { Models } \\
\text { Equations } \\
\text { Variable }\end{array}$} & \multicolumn{2}{|c|}{ (1) $\sigma_{i} \&$ OPTION/TOTAL_COMP } & \multicolumn{2}{|c|}{ (2) $\sigma_{i} \&$ ACCUMULATED_OPTION } \\
\hline & OPTl & TAL_COMP & $\sigma_{j}$ & ACCUMULATED_OPTION \\
\hline & Equation 1 & Equation 2 & Equation 1 & Equation 2 \\
\hline OPTION/TOTAL_COMP & $\begin{array}{l}0.00028 \\
(2.17)^{* *}\end{array}$ & - & - & - \\
\hline ACCUMULATED_OPTION & & - & $\begin{array}{l}0.00021 \\
(4.86)^{* * *}\end{array}$ & - \\
\hline$\sigma_{j}$ & - & $\begin{array}{l}1065.1 \\
(3.13)^{* * * *}\end{array}$ & - & $\begin{array}{l}1877.65 \\
(5.93) * * *\end{array}$ \\
\hline LN(TA) & $\begin{array}{l}-0.00123 \\
(-3.73) * * *\end{array}$ & $\begin{array}{l}2.191 \\
(3.13)^{* * * *}\end{array}$ & $\begin{array}{l}-0.0015 \\
(-6.12)^{* * *}\end{array}$ & $\begin{array}{l}2.5616 \\
(3.93) * * *\end{array}$ \\
\hline CAPITAL_RATIO & $\begin{array}{l}-0.27 \\
(-1.83) * *\end{array}$ & - & $\begin{array}{l}-0.08 \\
(-6.21)^{* *}\end{array}$ & - \\
\hline NON_INT_INCOME\% & $\begin{array}{l}0.0012 \\
(0.27)\end{array}$ & - & $\begin{array}{l}-0.0025 \\
(-0.83)\end{array}$ & - \\
\hline GEO_DUMMY & $\begin{array}{l}-0.0009 \\
(-0.99)\end{array}$ & - & $\begin{array}{l}0.0006 \\
(0.85)\end{array}$ & - \\
\hline STOCK_PRICE & - & $\begin{array}{l}0.0758 \\
(2.69) * * *\end{array}$ & - & $\begin{array}{l}0.157 \\
(5.99) * * *\end{array}$ \\
\hline D92 /DRate92 & $\begin{array}{l}0.0059 \\
(3.8)^{* * *}\end{array}$ & $\begin{array}{l}-1.842 \\
(-1.88)^{*}\end{array}$ & $\begin{array}{l}0.0055 \\
(5.54)^{* * *}\end{array}$ & $\begin{array}{l}-0.3406 \\
(-0.37)\end{array}$ \\
\hline D93 / DRate93 & $\begin{array}{l}0.0056 \\
(3.15)^{* * *}\end{array}$ & $\begin{array}{l}-1.054 \\
(-0.89)\end{array}$ & $\begin{array}{l}0.0052 \\
(4.98)^{* * *}\end{array}$ & $\begin{array}{l}0.6085 \\
(0.55)\end{array}$ \\
\hline D94 / DRate94 & $\begin{array}{l}0.0022 \\
(1.42)\end{array}$ & $\begin{array}{l}0.7567 \\
(0.88)\end{array}$ & $\begin{array}{l}0.0024 \\
(2.37)^{* * *}\end{array}$ & $\begin{array}{l}0.4149 \\
(0.52)\end{array}$ \\
\hline D95 / DRate95 & $\begin{array}{l}0.00006 \\
(0.05)\end{array}$ & $\begin{array}{l}-1.1032 \\
(-1.77)^{*}\end{array}$ & $\begin{array}{l}0.0003 \\
(0.36)\end{array}$ & $\begin{array}{l}-0.3342 \\
(-0.57)\end{array}$ \\
\hline D97 /D Rate97 & $\begin{array}{l}0.0033 \\
(2.66)^{* * *}\end{array}$ & $\begin{array}{l}0.404 \\
(0.57)\end{array}$ & $\begin{array}{l}0.0029 \\
(3.11)^{* * *}\end{array}$ & $\begin{array}{l}1.0367 \\
(1.58)\end{array}$ \\
\hline D98 /D Rate98 & $\begin{array}{l}0.0095 \\
(7.68)^{* * *}\end{array}$ & $\begin{array}{l}1.592 \\
(2.3)^{*}\end{array}$ & $\begin{array}{l}0.0093 \\
(10.15)^{* * *}\end{array}$ & $\begin{array}{l}1.0771 \\
(1.67)^{*}\end{array}$ \\
\hline D99 / DRate99 & $\begin{array}{l}0.0071 \\
(5.47)^{* * *}\end{array}$ & $\begin{array}{l}3.591 \\
(4.7)^{* * *}\end{array}$ & $\begin{array}{l}0.0071 \\
(7.55)^{* * *}\end{array}$ & $\begin{array}{l}0.981 \\
(1.38)\end{array}$ \\
\hline D00 / DRate00 & $\begin{array}{l}0.0136 \\
(10.53)^{* * *}\end{array}$ & $\begin{array}{l}1.259 \\
(2.0)^{* *}\end{array}$ & $\begin{array}{l}0.0139 \\
(14.65)^{* * *}\end{array}$ & $\begin{array}{l}1.4515 \\
(2.47)^{* * *}\end{array}$ \\
\hline $\mathrm{R}^{2}$ & $30 \%$ & $17 \%$ & $45 \%$ & $19 \%$ \\
\hline
\end{tabular}

$\sigma_{j}$ is a measure of total risk; OPTION/TOTAL_COMP is the percentage of total compensation in the form of stock options; ACCUMULATED_OPTION is the accumulated option value measuring the executive's wealth; LN(TA) is the natural $\log$ of total assets; CAPITAL_RATIO is the capital-to-assets ratio; NON_INT_INCOME\% is the percentage of income that is from non-interest sources; GEO_DUMMY is a binary variable measuring geographic diversification; and Dum92 - Dum00 are dummy variables coded as 1 or 0 for each year from 1992-2000. 1995 is the excluded year.

$* * *, * *, *$ indicates significance at the 1 percent, 5 percent and 10 percent levels respectively. 


\section{Summary and concluding remark}

Rarely a single equation arises in economic theory. In a multi-equation system, OLS fails to yield unbiased and consistent estimators for the structural equations. Therefore, appropriate estimation methods must be applied to the estimation of structural equation parameters. This paper first discusses situations where a simultaneous equation system may arise. We then explain why OLS estimation is not appropriate. Section B introduces two most frequently used methods to estimate structural parameters in a system of equations. Before 2SLS and 3SLS methods are synthesized, we explain the order condition and the rank condition of model identification. 2SLS and 3SLS are then introduced, and the differences between these two methods are discussed. Section $C$ gives examples from the literature where applications of the simultaneous equation models in finance are shown. In the finance application, Chen et al. (2006) employ a two-equation model to examine the relationship between executives' incentive compensation and firm risk-taking. Because both executive compensation and firm risk are endogenous, 2SLS is more appropriate than OLS method.

When deciding on the appropriate method to estimate structural equations, one must be cautious that in the real world the distinction between endogenous and exogenous variables are often not as clear-cut as one would like to have. Economic theory, therefore, must play an important role in the model construction. Furthermore, as explained in Section B, although full information methods produce more efficient estimation, they are not always better than the limited information method. This is because, for example, 3SLS is vulnerable to model specification errors. If an equation is mis-specified, the error will propagate into the entire system of equations.

\section{E. References}

Blalock, H.M., (1969), Theory Construction: From Verbal to Mathematical Formulations, Prentice-Hall, Englewood Cliffs, New Jersey.

Chen, C.R., T. Steiner, and A. Whyte, (2006), "Does Stock Option-Based Executive Compensation Induce Risk-Taking? An Analysis of the Banking Industry." Journal of Banking and Finance (30), pp. 915-946.

Fisher, F.M., (1966), the Identification Problem in Econometrics, McGraw-Hill, New York, NY.

Fogler, H.R., and S. Ganapathy, (1982), Financial Econometrics, Prentice-Hall, Englewood 
Cliffs, New Jersey.

Ghosh, S.K., (1991), Econometrics: Theory and Applications, Prentice Hall, Englewood Cliffs, New Jersey.

Greene, W.H., (2003), Econometric Analysis, Prentice Hall, Upper Saddle River, New Jersey.

Judge, G.G., W.E. Griffiths, R.C. Hill, H. Lütkepohl, and T. Lee, (1985), The Theory and Practice of Econometrics, John Wiley \& Sons, New York, New York.

Ramanathan, R. (1995), Introductory Econometrics with Application, the Dryden Press, Fort Worth, Texas. 